\title{
LEARNING TO READ IN ADULTHOOD: AN EVALUATION OF A LITERACY PROGRAM FOR FUNCTIONALLY ILLITERATE ADULTS IN GERMANY \\ Volume 51, 2013
}

\author{
Melanie Boltzmann, Jascha Rüsseler \\ University of Bamberg, Bamberg, Germany \\ E-mail: Melanie.Boltzmann@uni-bamberg.de, Jascha.Rüsseler@uni-bamberg.de \\ Zheng Ye \\ Cambridge University, Cambridge, Great Britain \\ E-mail: zy250@medschl.cam.ac.uk \\ Thomas F. Münte \\ University of Lübeck, Lübeck, Germany \\ E-mail: Thomas.Muente@neuro.uni-luebeck.de
}

PROBLEMS

OF EDUCATION

IN THE $21^{\text {st }}$ CENTURY

\begin{abstract}
It is estimated that 759 million individuals worldwide are illiterate, i.e. they cannot read or write properly. With 95\%, the majority of the illiterate population lives in developing countries. In most cases, these individuals did not attend school and, therefore, did not have the chance to acquire any skills in reading and writing. They are referred to as primary illiterates. However, illiteracy is not restricted to developing countries: In developed countries there are individuals who have great difficulties with reading and writing despite attending school for several years; they are termed as functional illiterates. For most individuals, the ability to read and write is crucial for being employed and socially accepted. Thus, education is an essential prerequisite for personal growth and satisfaction with life. The present research presents an innovative approach to overcome deficits in reading and writing in adults. The effectiveness of the program was investigated in two courses, each comprising 18 German functionally illiterate adults. Results show that participation in the program was accompanied by improved literacy skills and neuronal changes measured with fMRI.
\end{abstract}

Key words: adulthood, fMRI, evaluation, functional illiteracy, reading and writing, training program.

\section{Introduction}

Almost one fifth of the world's adult population is not literate. However, literacy rates differ significantly among countries, ranging between $90 \%$ in North America and Europe (e.g., Canada, the Baltic States or Finland) and below $30 \%$ in sub-Saharan Africa (Mali, Burkina Faso, Ethiopia, Niger; UNDP, 2011).

The main reason for these differences in literacy rate is the access to education between countries. In developing countries, illiteracy is mainly due to social reasons like poverty, child labor, lack of schools or disapproval of literacy (Ardila et al., 2010). Most adults have never attended school and thus were never been taught how to read and write. Consequently, they are often unable to read and write at all in any language and are referred to as primary illiterates.

Since literacy rates usually increase with years of formal education, illiteracy should not be a problem in countries where education is compulsory. Yet, even in those countries there 
PROBLEMS

OF EDUCATION

IN THE $21^{\text {st }}$ CENTURY

Volume 51,2013

34

are individuals who have only rudimentary literacy skills despite attending school for several years. These adults can use written language to a very limited extent. For example, a person may be able to fill in personal details on a form, but display poor comprehension and use of printed information in daily life at home, at work and in the community (writing out a cheque; reading a letter; addressing an envelope; reading a patient information leaflet; helping your primary school child with easy written language tasks etc.). If the acquired skills are below the level necessary to maintain employment and to participate adequately in society, individuals are characterized as functional illiterates.

Functional illiteracy is often associated with specific personal obstacles in childhood concerning school (truancy, inappropriate instructions, repetition of classes) and family environment (neglect, drug abuse of parents, abuse, numerous siblings etc.). However, these negative experiences do not apply for all individuals with low literacy skills, and are also not sufficient to let someone become illiterate (Eme, 2010). Accordingly, functional illiteracy is most likely caused by multiple factors. Recently, researchers began to consider that functional illiteracy could result from cognitive deficits coupled with environmental disadvantages (Eme, 2010; Greenberg \& Ehri, 2002; Greenberg, Ehri \& Perin, 1997).

In Germany, 7.5 million people between 18 and 64 years are considered functionally illiterate (14.5\% of the adult population; Grotlüschen \& Riekmann, 2012). Functional illiterates are able to read and write simple single words but have difficulties with reading and writing even short sentences. For example, they are unable to read information in TV-guides or train time-tables. With $60.3 \%$ the majority of the functionally illiterate population in Germany is male. $80.4 \%$ are German native speakers, whereas $19.6 \%$ are migrants with good oral knowledge of the German language. The majority of functional illiterates in Germany have a school leaving certificate $(80.7 \%$ ), but only $56 \%$ completed a vocational training. $56.9 \%$ are employed, but they often work in areas which require low professional qualifications (Grotlüschen \& Riekmann, 2012). The lack of basic education of adults has serious economic consequences, as companies have increasing difficulties finding employees with adequate skills in reading and writing. As social and work-related demands increase continuously, reading and writing skills which would have been considered adequate in the past are often no longer sufficient to maintain employment. Fewer jobs can be performed successfully if employees have problems with reading and writing (Fowler \& Scarborough, 1993).

\section{Problem of Research}

Recent data indicate that in Germany, only a fraction of the functional illiterates attend literacy courses for adults; in 2009 approx. 31.000 adults (Rosenbladt \& Bilger, 2013). Based on the number of 7.5 million functional illiterates in Germany, the proportion of persons who attend literacy classes is extremely low $(0.41 \%)$. In addition, most basic literacy courses primarily aim at promoting basic reading and writing skills. Offers specific to workplace literacy are the exception. Thus, there seems to be a need for the development of literacy education courses especially aimed at the adult population.

\section{Research Focus}

The present research describes a special literacy training that was developed for functionally illiterate adults in Germany (Alpha plus). The effectiveness of Alpha plus was investigated using fMRI. The research focused on examining whether changes in literacy skills are associated with neuronal changes in brain regions relevant for reading. 


\section{Methodology of Research}

$\mid \begin{aligned} & \text { PROBLEMS } \\ & \text { OF EDUCATION } \\ & \text { IN THE 21 } 1^{\text {st }} \text { CENTURY } \\ & \text { Volume 51, } 2013\end{aligned}$

General Background of Research

The training program Alpha plus was developed in a joint effort of the Psychology department of the University of Bamberg, a company for medical electronic goods and an educational institute.

The program is designed for adults who attended school but have severe and persisting problems with written language tasks in their everyday life. It is aimed at native German speakers. The lack of reading and writing skills often leads to problems in getting and maintaining a job. The aim of the program is to teach reading and writing to functionally illiterate adults with the main goal of integrating participants in employment. This will open up new perspectives for participating in society and for gaining economic independence.

\section{Sample of Research}

30 healthy adults participated in the present study. The experimental group consisted of 20 functionally illiterate adults who took part in Alpha plus (15 male; mean age: $42.55 \pm 9.28$ years, range: 25 to 58 years). Members of this group were recruited by collaborators of local job centers and participated voluntarily. They did not attend any other literacy courses for adults prior to their participation in the present course. A group of 10 functionally illiterate adults who received conventional literacy training was used as control group ( 7 male; mean age: $42.00 \pm 11.27$ years, range: 29 to 67 years). Conventional literacy courses are usually offered by adult education centers. Courses take place once a week for one and a half hour per session. Subjects attended these courses for about 3 years $(M=3.06 \pm 2.70$ years $)$. The group is used as control group to compare the outcomes of Alpha plus with the outcomes of conventional literacy courses. However, the comparison is limited to changes in literacy skills because fMRI data are not available for functional illiterates attending conventional literacy courses, due to organizational reasons.

\section{Instrument and Procedures}

The study consisted of two fMRI scanning sessions (eight months apart) with the same experimental setting. Participants were instructed to silently read pairs of words, pseudo-words or letter strings. In the word and pseudo-word condition they were asked to press button one if the words or pseudo-words rhymed and button two if the words or pseudo-words did not rhyme. In the letter string condition they had to decide whether the letter strings were the same (button one) or different (button two). Responses had to be executed with the index finger of the right hand on an MR-compatible response-pad.

Each run started with a visually presented yellow smiley to allow the magnetic resonance signal to reach equilibrium. A trial began with a white fixation cross lasting for $10 \mathrm{~s}$, then one pair of words, pseudo-words or letter strings was presented for $5 \mathrm{~s}$. The reaction phase was indicated by a red fixation cross that lasted for $1 \mathrm{~s}$ (see Figure 1). Fixation crosses and stimuli were presented with long durations to ease the reading process for the participants. 
PROBLEMS

OF EDUCATION

IN THE $21^{\text {st }}$ CENTURY

Volume 51, 2013

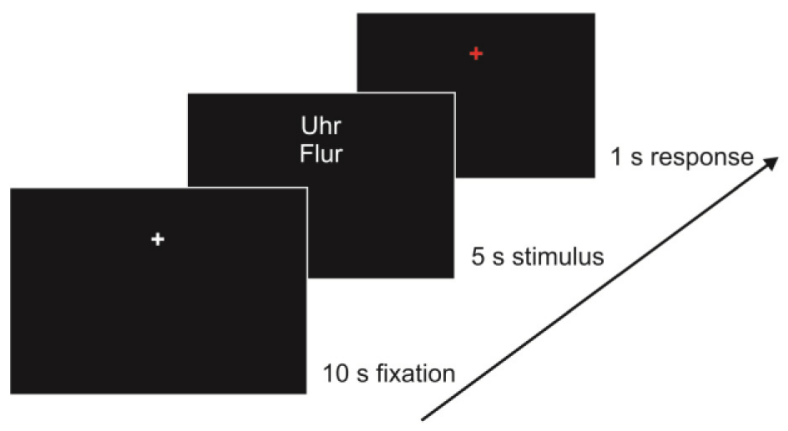

Figure 1: Study design illustrated for words.

The stimuli were presented in white on a black screen of an MRI-compatible video display integrated into a prepared pair of glasses. A total of 30 pairs of stimuli in each condition were presented in subsequent runs. Stimuli in the word condition were concrete nouns derived from schoolbooks for first-graders with a length between three and six letters (e.g. Uhr - Flur [watch - corridor]). The stimuli for the pseudo-word condition were pronounceable nonsense words constructed according to the phonological and orthographical rules of the German language (e.g. Meu - Weu). The 15 pseudo-words for the rhyming condition were created by changing the first letter of an existing pseudo-word. The letter strings consisted of randomly chosen letters that were slightly changed when both strings of a pair had to be different (one letter changed position or one letter changed entirely). Length of pseudo-words and letter strings matched the length of words. In each condition 15 pairs of stimuli rhymed (words, pseudowords) or were the same (letter strings), whereas the other 15 pairs did not rhyme or were different. The order of the trials within each condition was pseudo-randomized and the three functional runs were counterbalanced across participants. Between each run a short rest was given. Stimuli were delivered by Presentation software, version 14.5 (Neurobehavioral Systems Inc., www.neurobs.com). Prior to the scanning session, participants were thoroughly prepared by training with test trials outside the scanner to ensure that they fully understood the task.

\section{Description of the Training Program Alpha plus}

The subjects participated in a training program specifically developed for functionally illiterate adults (Alpha plus). Functional illiterates are often ashamed of their deficits and constantly afraid of public humiliation. Consequently, they run a high risk of social withdrawal. Therefore, the main objective of the training program was to improve the reading and writing skills in a way that the participants would be able to self-organize their daily life and overcome their social isolation.

The training program was implemented in two courses that were offered over a period of nine months, i.e. from March until November 2009 (course 1) and 2010 (course 2), respectively. Altogether, 36 functionally illiterate adults participated in the program (18 in each course). 20 of these participants agreed to take part in the fMRI study. Only their data are presented. Professional tutors conducted the program in a local educational institute in northern Germany. Lessons took place from Monday to Friday between $8.30 \mathrm{am}$ and $2 \mathrm{pm}$. The training consisted of three main modules with different methodological foci. First, the basic rules of mapping graphemes to phonemes were taught in conventional literacy lessons (approx. $2 \mathrm{hrs}$. daily). This approach is similar to instructions given to children during regular literacy acquisition. Specific paper-pencil based exercises were developed due to the lack of appropriate educational materials for adult basic education. The training material was highly relevant to the everyday issues of the participants in order to achieve sustained success of the training and to ensure that the participants will engage in reading and writing in their everyday life. The training began with 
reading syllables; later, short words and sentences were used. One of the main objectives was that participants learn the rules of mapping graphemes to phonemes and internalize the phonological structure of words. It was important to ensure that the participants really read the words by phoneme-grapheme-conversion and not just by rote memorization. Common German letter combinations were trained intensively.

The second module was characterized by the use of technical devices to train different skills relevant for language processing (approx. 2 hrs. daily). This part of the training was supposed to consolidate the achievements made during conventional reading lessons. Participants trained with a tool called BrainBoy ${ }^{\circledR}$ to improve their basic visual and auditory perceptual abilities. In eight subtests, participants have to discriminate different features of tones or light flashes (for more information see www.meditech.de; Rüsseler et al., 2012). In addition, audiovisual integration processes were trained with a tool called AlphaTrainer. Linguistic stimuli like words are visually shown on a computer screen and simultaneously vocalized by a speaker, whose voice is presented via headphones. The participants themselves have to vocalize the presented stimuli into a microphone. The two language streams (speaker's voice and participants' voice) are distinctly perceived either with the left or with the right ear, and they change in opposite directions (e.g., speaker's voice from left to right, own voice from right to left). The input sides of the two language streams constantly change after a few seconds. It is assumed that the synchronous reading of letters and the vocalizing of words facilitates the audio-visual integration of letters and speech sounds. This idea is based on findings showing that dyslexics have deficits in audio-visual integration (Blau et al., 2009). Moreover, training of audio-visual integration has previously been shown to improve literacy skills in dyslexic children (Kujala et al., 2001; Magnan et al., 2004).

Finally, the discrimination of phonemes or consonants with similar sound structures was trained. To this purpose, three-letter nonsense words were presented via headphones. All of them had as first letter an "e" and as last letter an "i". The central character was always a consonant, which varied from trial to trial (e.g., "ebi", "eki", "epi”). The participants were asked to type the perceived middle character on a computer keyboard.

Social activities like shopping in the supermarket, cooking, visiting the stadium of the local soccer team or fire department were also part of the program. This social training finally constitutes the third module of the program.

\section{Cognitive Testing}

The Culture Fair Test (CFT; Weiß, 1998) was used to assess overall intelligence. The CFT is supposed to measure fluid intelligence independent of verbal fluency, cultural background, and educational level. The four subtests (series, classifications, matrices, conditions) are non-verbal and require participants to figure out relationships between shapes and figures. In the present study, scale 2 (German version) was used because it is applicable for adults with basic education. Only form A was applied in order to reduce the test time. Subjects were included in the study if they had an IQ of 70 or above.

Reading ability of functionally illiterate adults was assessed with the WLLP (Würzburger Leise-Leseprobe; Küspert \& Schneider, 1998). In this test, 140 written words as well as four pictures next to each word are presented. Participants have to mark the one picture that represents the word on the left side. The test score comprises the number of correctly identified pictures in five minutes. The WLLP is supposed to measure silent reading speed and the ability to decode written words. To assess the writing ability of functional illiterates, a standardized German test for the first grade was used (Diagnostischer Rechtschreibtest (DRT 1), Müller, 2004). Here, participants have to write 32 single words from dictation. We used parallel versions of the WLLP and DRT 1 at the beginning and at the end of the training in order to examine whether the reading and writing abilities had changed over time. 
$\begin{array}{r}\text { PROBLEMS } \\ \text { OF EDUCATION } \\ \text { IN THE 21 } 1^{\text {st }} \text { CENTURY } \\ \text { Volume } 51,2013 \\ \hline 38\end{array}$

To examine participants' behavioral performance, the number of correct responses and response times were assessed. These data were entered into a repeated measures ANOVA with the within subject factors STIMULUS TYPE (3 levels) and SESSION (2 levels). Follow-up paired-sample t-tests were used to further investigate differences. Altogether, these analyses were carried out to test whether participants were more accurate and faster after nine months of training.

FMRI data (three functional runs acquired on a 3-T MRI scanner pre and post training) were analyzed with SPM8. The first three volumes of each run were discarded owing to equilibration effects. Functional images were first phase-shifted with reference to the middle slice in time to correct for differences in slice acquisition time. They were then realigned with a least squares approach and a rigid body spatial transformation to remove artifacts. Realigned images were normalized to the EPI-derived MNI template. Normalized images were finally smoothed with a Gaussian kernel of 8-mm full-width half-maximum and filtered with a high-pass filter of 128s. We performed a standard univariate analysis to examine whether and how brain activity was modulated by stimulus type (real word vs. pseudo-word vs. letter string) during training (post vs. pre-test). Three types of events were specified and time-locked to their onsets: the real word, the pseudo-word and the letter string. Events with correct responses and those with incorrect or no responses were separately modeled. For each event with a correct response, reaction time was included as parametric parameter to account for trial-specific effects. Estimated movement parameters were also involved in the model to minimize signal-correlated motion effects. Classical parameter estimation was applied with a one-lag autoregressive model (AR(1)). Contrast maps were calculated for each stimulus type (only for events with correct responses) as compared with signal baseline and entered into a flexible factorial design with two factors, SESSION (2 levels) and STIMULUS TYPE (3 levels). Main effects of SESSION (post $>$ pre-test) and STIMULUS TYPE (real word $>$ letter string; pseudo-word $>$ letter string) were computed. Resulting maps were considered at $\mathrm{p}<0.005$ at voxel level and $\mathrm{p}<0.05$ (FDRcorrected) at cluster level.

\section{Results of Research}

\section{Descriptive Statistics}

Table 1 gives descriptive characteristics of the two functionally illiterate groups for the variables sex, age, handedness, non-verbal IQ, reading and writing abilities. Overall, participants had an average non-verbal IQ of 87.57 (9.38) with scores ranging from 71 to 108. Members of the experimental and the control group were matched for non-verbal IQ $\left(\mathrm{t}_{28}=-1.05\right.$, $\mathrm{p}=0.30)$, age $\left(\mathrm{t}_{28}=-0.14, \mathrm{p}=0.89\right)$ and pretest reading ability $\left(\mathrm{t}_{28}=-1.23, \mathrm{p}=0.23\right)$.

Reading and writing skills of both groups were analyzed using a two-way, repeated measures ANOVA with two levels of SESSION (pretest vs. posttest) and two levels of GROUP (experimental vs. control group).

For reading, the ANOVA revealed a significant main effect of SESSION $\left(\mathrm{F}_{1,28}=10.79\right.$, $\mathrm{p}<0.01)$ and a significant interaction of SESSION by GROUP $\left(\mathrm{F}_{1,28}=4.56, \mathrm{p}<0.05\right)$. Posthoc paired $t$ tests showed that the reading scores improved over time $\left(\mathrm{t}_{29}=-4.00, \mathrm{p}<0.001\right)$. As indicated by the significant interaction, only trained functional illiterates improved their reading ability from pre- to posttest $\left(\mathrm{t}_{19}=-4.12, \mathrm{p}<0.01\right)$, while untrained functional illiterates did not show any considerable changes in their reading scores (see Figure 2-A).

For writing, a significant interaction of SESSION by GROUP was found $\left(\mathrm{F}_{1,28}=9.49\right.$, $\mathrm{p}<0.01)$. This effect is mainly due to the fact that the experimental group significantly reduced the number of errors in the standardized writing test $\left(\mathrm{t}_{19}=-6.21, \mathrm{p}<0.001\right)$, while there were no statistically reliable changes in the control group (see Figure 2-B). 
Melanie BOLTZMANN, Jascha RÜSSELER, Zheng YE, Thomas F. MÜNTE. Learning to Read in Adulthood: An Evaluation of a Literacy Program for Functionally Illiterate Adults in Germany

Table 1. Characteristics of participants: descriptive statistics of sex, handedness, age, non-verbal IQ, reading and writing ability.

\begin{tabular}{|c|c|c|c|}
\hline & & Experimental group $(n=20)$ & Control group $(n=10)$ \\
\hline Sex & & 15 males & 7 males \\
\hline Age & & $42.55(9.28)$ & $42.00(11.27)$ \\
\hline Handedness & & 15 right handed & 10 right handed \\
\hline non-verbal IQ & & $86.30(7.64)$ & $90.10(12.22)$ \\
\hline \multirow{2}{*}{$\begin{array}{l}\text { Reading: WLLP } \\
\text { (correct words) }\end{array}$} & $\mathrm{T} 1$ & $39.25(26.19)$ & $50.30(14.99)$ \\
\hline & $\mathrm{T} 2$ & $56.20(33.92)$ & $53.90(13.17)$ \\
\hline \multirow{2}{*}{ Writing: DRT (errors) } & $\mathrm{T} 1$ & $16.30(10.65)$ & $8.30(6.78)$ \\
\hline & $\mathrm{T} 2$ & $10.35(8.53)$ & $9.80(6.18)$ \\
\hline
\end{tabular}

(A) Reading ability

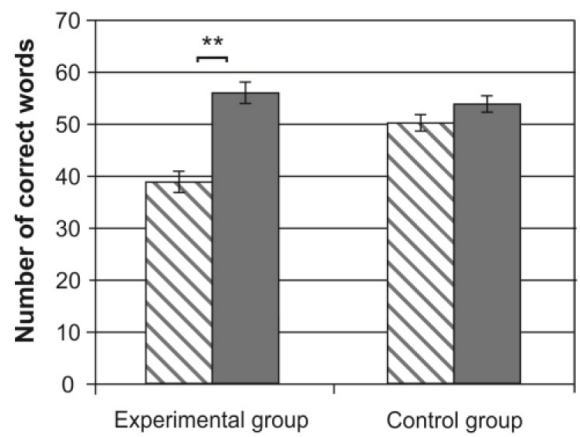

(B) Writing ability

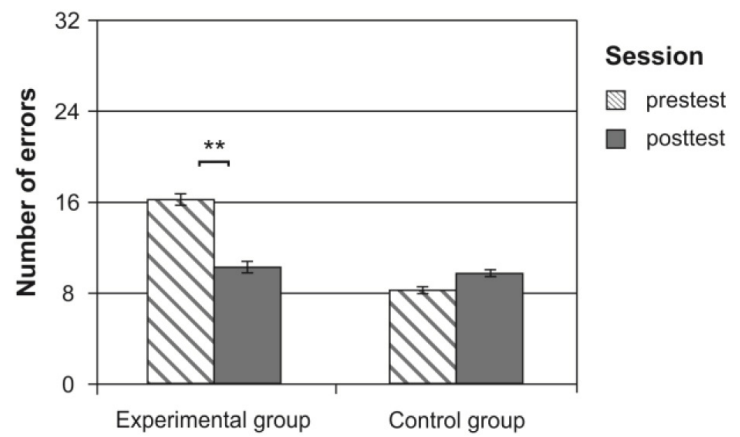

Figure 2: Reading (A) and writing (B) abilities of functionally illiterate adults at pre- and posttest.

\section{Behavioral Data}

Number of errors (errors + no response) and response times for words, pseudo-words and letter strings are presented in Table 2.

A two-way ANOVA with STIMULUS TYPE and SESSION was conducted to determine if there were changes in behavioral data from pre- to posttest. The number of errors was different for words, pseudo-words and letter strings (STIMULUS TYPE: $\mathrm{F}_{2.36}=31.22, \mathrm{p}<0.001$ ), but did not change from pre- to posttest. The main effect of STIMULUS TYPE is due to the fact that the performance for letter strings was higher than the performance for words $\left(\mathrm{t}_{19}=4.21\right.$; $\mathrm{p}<0.001)$ and pseudo-words $\left(\mathrm{t}_{19}=3.15, \mathrm{p}<0.01\right)$, while there was no difference between words and pseudo-words $\left(\mathrm{t}_{19}=1.35, \mathrm{p}=0.19\right)$. Additionally, response times were different depending on which stimulus type has been presented (STIMULUS TYPE: $\mathrm{F}_{2,36}=17.60, \mathrm{p}<0.001$ ). Responses for letter strings were clearly faster than responses for both words $\left(\mathrm{t}_{18}=4.98, \mathrm{p}<0.001\right)$ and pseudo-words $\left(\mathrm{t}_{18}=4.06, \mathrm{p}<0.001\right)$. There also was a significant interaction between STIMULUS TYPE and SESSION $\left(\mathrm{F}_{2,36}=4.99, \mathrm{p}<0.05\right)$, due to a better performance for letter strings after training $\left(\mathrm{t}_{18}=2.22, \mathrm{p}<0.05\right)$. 
PROBLEMS

OF EDUCATION

IN THE $21^{\text {st }}$ CENTURY

Volume 51, 2013

Table 2. Means and standard deviations for behavioral data.

\begin{tabular}{|c|c|c|c|}
\hline & & & Experimental group $(n=20)$ \\
\hline \multirow{6}{*}{ Errors } & \multirow{3}{*}{$\mathrm{T} 1$} & Words & $5.85(4.82)$ \\
\hline & & Pseudo-words & $5.10(4.87)$ \\
\hline & & Letter strings & $1.75(3.39)$ \\
\hline & \multirow{3}{*}{$\mathrm{T} 2$} & Words & $6.30(6.22)$ \\
\hline & & Pseudo-words & $5.40(4.82)$ \\
\hline & & Letter strings & $2.05(4.07)$ \\
\hline \multirow{6}{*}{ Response time in s } & \multirow{3}{*}{$\mathrm{T} 1$} & Words & $4.49(1.36)$ \\
\hline & & Pseudo-words & $4.38(1.33)$ \\
\hline & & Letter strings & $4.00(1.74)$ \\
\hline & \multirow{3}{*}{$\mathrm{T} 2$} & Words & $3.99(1.62)$ \\
\hline & & Pseudo-words & $3.96(1.64)$ \\
\hline & & Letter strings & $3.04(1.74)$ \\
\hline
\end{tabular}

FMRI Data

Table 3 and Figure 3 present the effects of SESSION and STIMULUS TYPE. The left inferior frontal gyrus (Broca's area), left postcentral gyrus (PCG), left basal ganglia and supplementary motor area (SMA) were more activated for real or pseudo-words than letter strings. The left fusiform gyrus (including the visual Word Form Area, vWFA; marked with green cycle) and lingual gyrus showed greater activations after training (post $>$ pre-test). An independent ROI analysis revealed an interaction between SESSION and STIMULUS TYPE in the vWFA. The activity in response to real words and letter strings were increased after training.

Table 3. Main effects of test and stimulus type in brain activity.

\begin{tabular}{llllllll}
\hline Region & BA & H & $\mathbf{x}$ & $\mathbf{y}$ & $\mathbf{z}$ & $\mathbf{t}$ & $\begin{array}{l}\text { Number of } \\
\text { voxels }\end{array}$ \\
\hline Post > Pre-test & & & & & & & \\
Fusiform gyrus/lingual gyrus & $19 / 18$ & $\mathrm{~L}$ & -12 & -91 & -13 & 3.64 & 175 \\
Real/pseudo-word > letter string & & & & & & & \\
Inferior frontal gyrus & $44 / 45 / 47$ & $\mathrm{~L}$ & -60 & 2 & 21 & 7.13 & 668 \\
Postcentral/precentral gyrus & 4 & $\mathrm{~L}$ & -54 & -7 & 40 & 7.31 & 617 \\
Supplementary motor area & 6 & $\mathrm{R}$ & 57 & -4 & 33 & 6.75 & 441 \\
Basal ganglia & & $\mathrm{L} / \mathrm{R}$ & -6 & 5 & 59 & 7.06 & 268 \\
\hline
\end{tabular}

BA, Brodmann Area; H, hemisphere; coordinates in MNI; t, statistic values of peaks; L, left; R, right. 


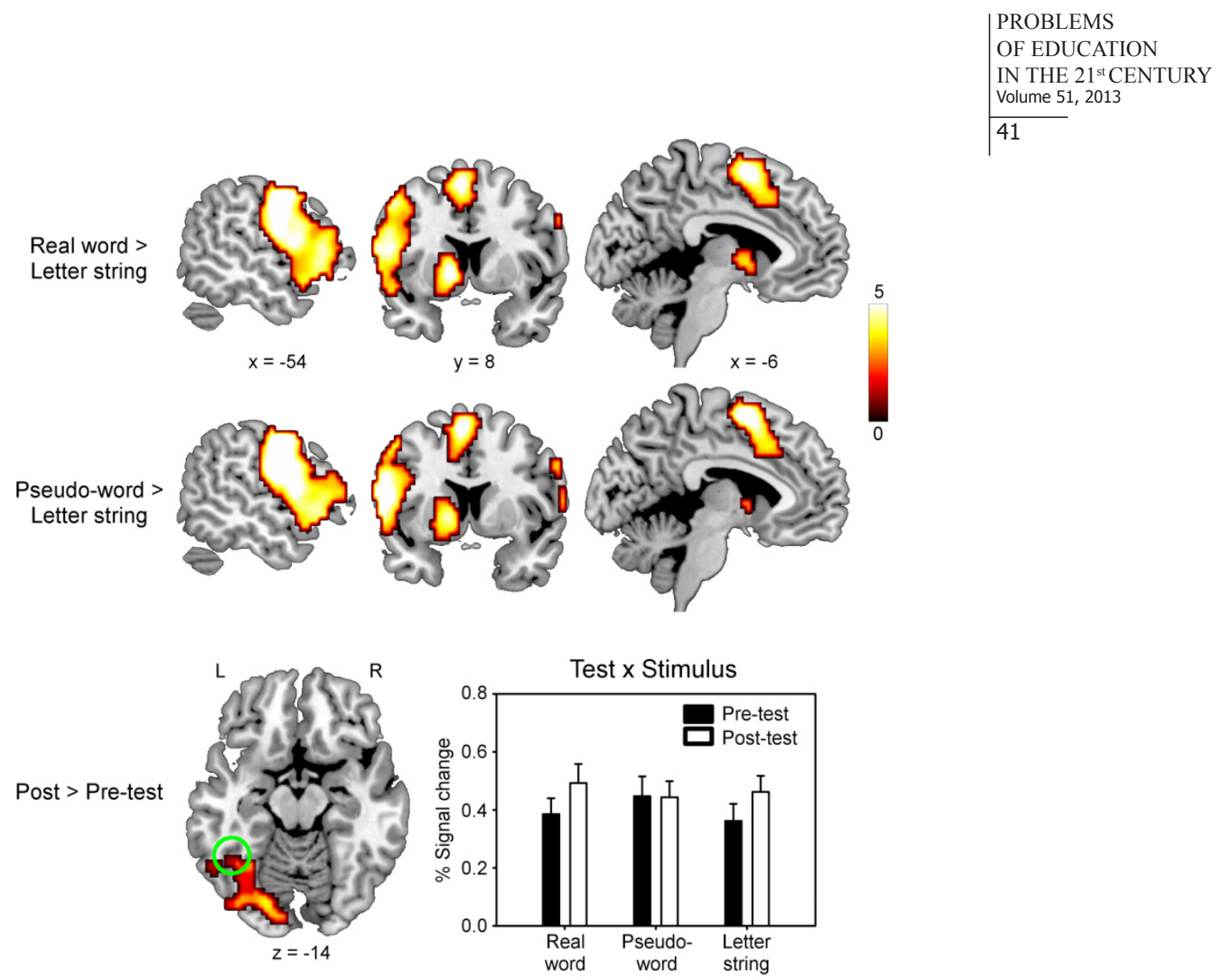

Figure 3: Brain activity modulated by SESSION (post > pre-test) and/or STIMULUS TYPE (real word > letter string, or pseudo-word > letter string). $L$, left; R, right; Coordinates in MNI. Color scale indicates $t$ values. Bar graph shows the interaction of test and stimulus type in values of percent signal changes extracted from the visual word form area. Bars indicate means and error bars indicate standard errors.

\section{Discussion}

This study examined whether functionally illiterate adults show an increased activity in reading-related brain regions after nine months of intensive literacy training. Subjects gained in reading and writing ability due to the participation in the training.

\section{FMRI Data}

Standard univariate fMRI analysis revealed higher activation levels for real words and pseudo-words relative to letter strings in the inferior frontal gyrus, left postcentral gyrus, left basal ganglia and supplementary motor area (SMA).

Inferior frontal regions are usually engaged when words have to be read by graphemephoneme-conversion due to unknown or infrequent phonological representations. According to psycholinguistic models, novel readers strongly use grapheme-to-phoneme rules to decode written words. At this level, children consistently activate frontal brain regions comprising the inferior frontal gyrus (Schlaggar et al., 2002; Simos et al., 2001). Frontal brain regions are also engaged when adults have to perform complex phonological tasks (e.g., pseudo-word rhyming) and when they read infrequent words and pseudo-words (Fiebach et al., 2002; Fiez \& Petersen, 
PROBLEMS

OF EDUCATION

IN THE $21^{\text {st }}$ CENTURY

Volume 51,2013

42

1998; Shaywitz et al., 1998). Pseudo-words are pronounceable word forms, which have no entry in the mental lexicon and therefore require phonological decoding. Altogether, the empirical data indicate that novel as well as experienced readers rely on frontal regions when they read words with unknown or unfamiliar phonological representations.

The real word stimuli used in the present study, although frequent words in German, are likely to be less familiar to functionally illiterate adults as they have problems reading even simple words. Accordingly, functionally illiterate adults probably read real words as well as pseudo-words by using grapheme-to-phoneme conversion, similar to children learning to read. Their strong reliance on frontal brain regions resembles brain activations of children during reading.

Increased activity for words and pseudo-words compared to letter strings was also observed in the basal ganglia (caudate nucleus), left postcentral gyrus and supplementary motor area (SMA). The caudate nucleus is associated with motor control. The supplementary motor area (SMA) contributes to motor aspects of speech production (Fiez \& Petersen, 1998). It has been demonstrated that the SMA and other regions get more activated by words and pseudowords than by letter strings (e.g. Kronbichler et al., 2006). Our results are in line with previous findings, and indicate that real words and pseudo-words, both legitimate word forms, invoke speech production processes.

Another main finding of the univariate analysis is that the fusiform gyrus, which was not activated at pretest, showed considerable activity after nine months of training. The fusiform region is usually associated with the recognition of familiar orthographical word forms (e.g., Binder et al., 2003; Dehaene et al., 2002; Fiebach et al., 2002). Studies found stronger activation for words (Büchel, Price \& Friston, 1998; Cohen et al., 2002; Price, Wise \& Frackowiak, 1996; Xu et al., 2001) and pseudo-words (Devlin et al., 2006) in contrast to letter strings. Several functional imaging studies examining the development of this region during reading acquisition, reveal an increase of activity in the left hemisphere with reading experience (Schlaggar et al., 2002; Shaywitz et al., 2002; Simos et al., 2001) and a decrease of activity in the right hemisphere (Simos et al., 2001; Turkeltaub et al., 2003; Turkeltaub et al., 2005). The ROI analysis further demonstrated that the activity for words was significantly enhanced after nine months of training in the visual word form area. This is in line with psycholinguistic models of reading and experimental studies. Skilled readers invoke this region to recognize well-known words for which they have developed a visual expertise (for review see Schlaggar \& McCandliss, 2007).

The results for the comparison between pseudo-word and real word activation are somewhat more conflicting. Whereas in some studies no differences between words and pseudowords were found (Dehaene et al., 2002; Wydell et al., 2003), other studies observed greater activation to pseudo-words than to words (Fiez et al., 1999; Xu et al., 2001). These findings indicate that the orthographic regularity of linguistic stimuli rather than their lexical status determines activity in the fusiform gyrus (Binder et al., 2006; Cohen et al., 2002; Dehaene et al., 2005). The present results are not consistent with these results as we found that the fusiform gyrus responded significantly higher to words and letter strings, but not to pseudo-words. Pseudo-words strongly require phonological decoding by grapheme-to-phoneme conversion and may therefore be exclusively processed by frontal regions in the group of functionally illiterate adults. The training especially included reading simple common nouns that are quite similar to the stimuli used in the real world condition. Hence, it can be concluded that the subjects developed a certain expertise for these stimuli which is reflected in enhanced fusiform activity. Pseudo-words on the other hand remained very difficult to encode and therefore required phonological encoding instead of whole-word recognition.

In contrast to other studies, the activity for letter strings was also enhanced after training. In most studies examining visual word recognition, stimuli are presented in fast succession (e.g., $200 \mathrm{~ms}$ ), so that legitimate word forms as real words and pseudo-words can be identified, but illegitimate word forms as letter strings are difficult to recognize. In our study, the processing of letter strings was probably emphasized, because the stimuli were presented with 
an extended duration of $5 \mathrm{~s}$. Cohen et al. (2003), who displayed stimuli until a response was made, found similar results. Their study design implicated that subjects paid as much attention

PROBLEMS

OF EDUCATION

IN THE $21^{\text {st }}$ CENTURY

Volume 51, 2013

to letter strings as to real words allowing them to attentively scan the stimuli. Consequently, the activation of ventral regions was enhanced for both letter strings and real words. Altogether, findings indicate that the visual word form area may be activated by any orthographic stimuli, though the activity is modulated by orthographic legality of the stimuli and certain aspects of the experimental task.

\section{Evaluation of the Training Program Alpha plus}

Subjects participating in Alpha plus significantly improved their literacy skills and demonstrated neuronal changes in different brain areas. Functional illiterates attending conventional literacy courses did not improve their literacy skills. There may be various reasons accounting for this finding: First, conventional literacy courses are far less intensive. Second, conventional courses rely on similar teaching strategies used during literacy education of children. Since these same strategies already proved to be insufficient to teach functionally illiterate adults how to read and write in childhood, it seems reasonable to use additional methods.

We assume that problems in different areas, e.g. phonological processing, low-level perceptual functions, and audio-visual integration contribute to the deficits in literacy skills prevalent in functional illiterates. In order to overcome these deficits, the conventional literacy instruction, which was the main part of the program, was supplemented by specific methods (see methods section for more detailed information). These specific methods were based upon studies investigating deficits of dyslexic individuals. Dyslexics suffer among other things from deficits in low-level processing affecting the performance in auditory (Fischer \& Hartnegg, 2004), visual and audio-motor tasks (Fischer, Hartnegg \& Mokler, 2000). Training of those processes improves not only perceptual skills (Fischer et al., 2000), but also transfers to languagerelated phonological skills and writing abilities (Schäffler et al., 2004). Dyslexics also have an impaired audio-visual integration of sounds and pictures of letters. This deficit has been linked to an underactivation of the superior temporal cortex in dyslexics (Blau et al., 2009), an area associated with audio-visual integration. Auditory processing deficits have also been shown in functionally illiterate adults (Eme, 2010; Greenberg et al., 1997).

The present study has several shortcomings. First, we did not acquire fMRI data for the control group. This was done mainly for reasons of practicability. Second, the design of the present study does not allow conclusions with respect to the contribution of the single modules to the overall success of the training. Further research is required to investigate which of the employed training methods are essential for the training success.

\section{Conclusions}

The training program Alpha plus serves to teach reading and writing to functionally illiterate German adults. The participation in this course of nine months duration resulted in an improvement in reading and writing skills of the attending adults. Spelling accuracy as well as reading speed improved significantly. These improvements in literacy skills came along with changes in brain regions relevant for reading. Thus, it can be concluded that the program Alpha plus is an effective training program for teaching reading and writing competencies to functionally illiterate adults.

\section{Acknowledgement}

The authors declare that they have no financial interest in the outcome of the study. Funding was provided by the German Ministry of Education and Research (BMBF, grant no. 01AB074401 assigned to JR). The opinions that may be stated herein are those of the authors. 
PROBLEMS

OF EDUCATION

IN THE $21^{\text {st }}$ CENTURY

Volume 51,2013

44 We thank MediTech Electronics GmbH, Wedemark, Germany and the Bildungswerk der Niedersächsischen Wirtschaft (BNW), Hanover, for their kind cooperation in the project.

\section{References}

Ardila, A., Bertolucci, P. H., Braga, L. W., Castro-Caldas, A., Judd, T., Kosmidis, M. H., Matute, E., Nitrini, R., Ostrosky-Solís, F., \& Rosselli, M. (2010). Illiteracy: The neuropsychology of cognition without reading. Archives of Clinical Neuropsychology, 25 (8), 689.

Binder, J. R., McKiernan, K. A., Parsons, M. E., Westbury, C. F., Possing, E. T., Kaufman, J. N., \& Buchanan, L. (2003). Neural correlates of lexical access during visual word recognition. Journal of Cognitive Neuroscience, 15 (3), 372-393.

Binder, J. R., Medler, D. A., Westbury, C. F., Liebenthal, E., \& Buchanan, L. (2006). Tuning of the human left fusiform gyrus to sublexical orthographic structure. NeuroImage, 33 (2), 739-748.

Blau, V., van Atteveldt, N., Ekkebus, M., Goebel, R. \& Blomert, L. (2009). Reduced neural integration of letters and speech sounds links phonological and reading deficits in adult dyslexia. Current Biology, 19 (6), 503-508.

Büchel, C., Price, C., \& Friston, K. (1998). A multimodal language region in the ventral visual pathway. Nature, 394 (6690), 274-275.

Cohen, L., Lehéricy, S., Chochon, F., Lemer, C., Rivaud, S., \& Dehaene, S. (2002). Language-specific tuning of visual cortex? Functional properties of the Visual Word Form Area. Brain, 125 (5), 1054-1069.

Cohen, L., Martinaud, O., Lemer, C., Lehéricy, S., Samson, Y., Obadia, M., Slachevsky, A., \& Dehaene, S. (2003). Visual word recognition in the left and right hemispheres: Anatomical and functional correlates of peripheral alexias. Cerebral Cortex, 13 (12), 1313-1333.

Dehaene, S., Cohen, L., Sigman, M., \& Vinckier, F. (2005). The neural code for written words: A proposal. Trends in Cognitive Sciences, 9 (7), 335-341.

Dehaene, S., Le Clec'H, G., Poline, J., Le Bihan, D., \& Cohen, L. (2002). The visual word form area: a prelexical representation of visual words in the fusiform gyrus. NeuroReport, 13 (3), 321-326.

Devlin, J. T., Jamison, H. L., Gonnerman, L. M., \& Matthews, P. M. (2006). The role of the posterior fusiform gyrus in reading. Journal of Cognitive Neuroscience, 18 (6), 911-922.

Eme, E. (2010). Cognitive and psycholinguistic skills of adults who are functionally illiterate: Current state of research and implications for adult education. Applied Cognitive Psychology, 25 (5), 753762.

Fiebach, C. J., Friederici, A. D., Müller, K., \& Cramon, D. Y. von (2002). fMRI evidence for dual routes to the mental lexicon in visual word recognition. Journal of Cognitive Neuroscience, 14 (1), 11-23.

Fiez, J. A., Balota, D. A., Raichle, M. E., \& Petersen, S. E. (1999). Effects of lexicality, frequency, and spelling-to-sound consistency on the functional anatomy of reading. Neuron, 24 (1), 205-218.

Fiez, J. A., \& Petersen, S. E. (1998). Neuroimaging studies of word reading. Proceedings of the National Academy of Sciences of the United States of America, 95 (3), 914-921.

Fischer, B., \& Hartnegg, K. (2004). On the development of low-level auditory discrimination and deficits in dyslexia. Dyslexia, 10 (2), 105-118.

Fischer, B., Hartnegg, K., \& Mokler, A. (2000). Dynamic visual perception of dyslexic children. Perception, 29 (5), 523-530.

Fowler, A., \& Scarborough, H. S. (1993). Should reading-disabled adults be distinguished from other adults seeking literacy instruction: A review of theory and research. Technical Report No. 93-7.

Greenberg, D., \& Ehri, L. C. (2002). Do adult literacy students make the same word-reading and spelling errors as children matched for word-reading age? Scientific Studies of Reading, 6 (3), 221-243.

Greenberg, D., Ehri, L. C., \& Perin, D. (1997). Are word-reading processes the same or different in adult literacy students and third-fifth graders matched for reading level? Journal of Educational Psychology, 89 (2), 262-275.

Grotlüschen, A., \& Riekmann, W. (2012). Funktionaler Analphabetismus in Deutschland. Ergebnisse der ersten leo. - Level-One Studie. Münster: Waxmann.

Kronbichler, M., Hutzler, F., Staffen, W., Mair, A., Ladurner, G., \& Wimmer, H. (2006). Evidence for a dysfunction of left posterior reading areas in German dyslexic readers. Neuropsychologia, 44 (10), 1822-1832.

Kujala, T., Karma, K., Ceponiene, R., Belitz, S., Turkkila, P., Tervaniemi, M., \& Näätänen, R. (2001). 
Plastic neural changes and reading improvement caused by audiovisual training in reading-impaired children. Proceedings of the National Academy of Sciences of the United States of America, 98 (18), 10509-10514.

Küspert, P., \& Schneider, W. (1998). Würzburger Leise-Leseprobe (WLLP): Ein Gruppenlesetest für die Grundschule. Göttingen: Hogrefe.

Magnan, A., Ecalle, J., Veuillet, E., \& Collet, L. (2004). The effects of an audio-visual training program in dyslexic children. Dyslexia, 10 (2), 131-140.

Müller, R. (2004). Diagnostischer Rechtschreibtest für 1. Klassen (DRT 1). Göttingen: Beltz Test.

Price, C. J., Wise, R. J. S., \& Frackowiak, R. S. J. (1996). Demonstrating the implicit processing of visually presented words and pseudowords. Cerebral Cortex, 6 (1), 62-70.

Rosenbladt, B. Von, \& Bilger, F. (2013). Erwachsene in Alphabetisierungskursen der Volkshochschulen: Ergebnisse einer repräsentativen Befragung (AlphaPanel). Retrieved 2/23/2013 from http://www. grundbildung.de/fileadmin/redaktion/pdf/DVV-Projekte/Verbleibsstudie/2011-Bericht-AlphaPanel.pdf.

Rüsseler, J., Menkhaus, K., Aulbert-Siepelmeyer, A., Gerth, I., \& Boltzmann, M. (2012). „Alpha plus“: An innovative training program for reading and writing education of functionally illiterate adults. Creative Education, 3, 357-361.

Schäffler, T., Sonntag, J., Hartnegg, K., \& Fischer, B. (2004). The effect of practice on low-level auditory discrimination, phonological skills, and spelling in dyslexia. Dyslexia, 10 (2), 119-130.

Schlaggar, B. L., Brown, T. T., Lugar, H. M., Visscher, K. M., Miezin, F. M., \& Petersen, S. E. (2002). Functional neuroanatomical differences between adults and school-age children in the processing of single words. Science, 296 (5572), 1476-1479.

Schlaggar, B. L., \& McCandliss, B. D. (2007). Development of neural systems for reading. Annual Review of Neuroscience, 30, 475-503.

Shaywitz, B. A., Shaywitz, S. E., Pugh, K. R., Mencl, W. E., Fulbright, R. K., Skudlarski, P., Constable, R. T., Marchione, K. E., \& Fletcher, J. M. (2002). Disruption of posterior brain systems for reading in children with developmental dyslexia. Biological Psychiatry, 52 (2), 101-110.

Shaywitz, S. E., Shaywitz, B. A., Pugh, K. R., Fulbright, R. K., Constable, R. T., Mencl, W. E., Shankweiler, D. P., Liberman, A. M., Skudlarski, P., Fletcher, J. M., Katz, L., Marchione, K. E., Lacadie, C., Gatenby, C., \& Gore, J. C. (1998). Functional disruption in the organization of the brain for reading in dyslexia. Proceedings of the National Academy of Sciences of the United States of America, 95 (3), 2636-2641.

Simos, P. G., Breier, J. I., Fletcher, J. M., Foorman, B. R., Mouzaki, A., \& Papanicolaou, A. C. (2001). Age-related changes in regional brain activation during phonological decoding and printed word recognition. Developmental Neuropsychology, 19 (2), 191-210.

Turkeltaub, P. E., Gareau, L., Flowers, D. L., Zeffiro, T. A., \& Eden, G. F. (2003). Development of neural mechanisms for reading. Nature Neuroscience, 6 (6), 767-773.

Turkeltaub, P. E., Weisberg, J., Flowers, D. L., Basu, D., \& Eden, G. F. (2005). The neurobiological basis of reading: A special case of skill acquisition. In H. Catts, \& A. Kamhi (Eds.). The connection between language and reading disabilities (S. 105-130). Mahwah: Lawrence Erlbaum.

United Nations Development Programme [UNDP] (2011). Human Development Report 2011: Sustainability and equity: A better future for all. Retrieved 2/23/2013 from http://hdr.undp.org/en/media/ HDR_2011_EN_Complete.pdf.

Weiß, R. H. (1998). Grundintelligenztest Skala 2 CFT 20. Göttingen: Hogrefe.

Wydell, T. N., Vuorinen, T., Helenius, P., \& Salmelin, R. (2003). Neural correlates of letter-string length and lexicality during reading in a regular orthography. Journal of Cognitive Neuroscience, 15 (7), $1052-1062$.

Xu, B., Grafman, J., Gaillard, W. D., Ishii, K., Vega-Bermudez, F., Pietrini, P., Reeves-Tyer, P., DiCamillo, P., \& Theodore, W. (2001). Conjoint and extended neural networks for the computation of speech codes: The neural basis of selective impairment in reading words and pseudowords. Cerebral Cortex, 11 (3), 267-277. 
PROBLEMS

OF EDUCATION

IN THE $21^{\text {st }}$ CENTURY

Volume 51, 2013
Received: January 15, 2013
Accepted: March 11, 2013

\begin{tabular}{|ll|} 
Melanie Boltzmann & $\begin{array}{l}\text { Diploma in Psychology, Research Assistant, University of Bamberg, Markus- } \\
\text { platz 3, 96047 Bamberg, Germany. } \\
\text { E-mail: Melanie.Boltzmann@uni.-bamberg.de }\end{array}$ \\
\hline Jascha Rüsseler & $\begin{array}{l}\text { Prof. Dr. rer. nat., Professor, University of Bamberg, Markusplatz 3, } 96047 \\
\text { Bamberg, Germany. } \\
\text { E-mail: Jascha.Rüsseler@uni.-bamberg.de }\end{array}$ \\
\hline Zheng Ye & $\begin{array}{l}\text { Dr., Research Associate, Cambridge University, Department of Clinical } \\
\text { Neuroscience, Herchel Smith Building for Brain and Mind Sciences, Forvie } \\
\text { Site, Robinson Way, Cambridge CB2 0SZ, UK. } \\
\text { E-mail: zy250@medschl.cam.ac.uk }\end{array}$ \\
\hline Thomas Münte & $\begin{array}{l}\text { Dr., Professor, University of Lübeck, Clinic for Neurology, Ratzeburger Allee } \\
\text { 160, 23538 Lübeck, Germany. } \\
\text { E-mail: Thomas.Muente@neuro.uni-luebeck.de }\end{array}$
\end{tabular}

